\title{
Johns Hopkins wins new space institute
}

Princeton loses space telescope ground base

\section{Washington}

After racing neck-and-neck to the finishing line, Johns Hopkins University of Baltimore has beaten Princeton University to be the site for a new research institute responsible for the operation of the space telescope to be launched early in 1985. The Space Telescope Science Institute will be managed by the Association of Universities for Research in Astronomy (AURA), a 14-university consortium. The award of the contract to AURA was announced last week by Dr Robert Frosch shortly before he left his position as administrator of the National Aeronautics and Space Administration (NASA).

AURA already operates the group of telescopes on Kitt Peak in Arizona for the federal government. It selected Johns Hopkins as the proposed site last year even though the university itself is not a member of the consortium and does not at present have a major astronomy department. There were four other bids to operate the institute. Three of these would have put the institute at Princeton and the fourth, from the group which operates the Fermilab near Chicago, would have placed it near the particle accelerator.

The final choice was between AURA and the Princeton proposal from Associated Universities Inc., which already operates the National Radioastronomy Center and the Brookhaven National Laboratory. Dr Frosch accepted the recommendation of an evaluation team that the contract be awarded to AURA. It is thought that a deciding factor was the scope of the management scheme proposed by AURA, based largely on its Kitt Peak experience.

The new institute will be responsible for all aspects of the operation and use of the 2.4-metre optical telescope when it is launched into orbit 350 miles above the Earth from the space shuttle. Johns Hopkins University will provide a site and a new building on the edge of its Homewood campus, at a cost of about $\$ 6$ million. The AURA plan envisages an eventual staff of 150 people, including 40 full-time astronomers selected from around the world.

In addition, the institute is expected to take in up to 200 visiting scientists each year. They will be able to use the telescope 24 hours a day because, unlike surfacebased optical telescopes, the sky will be permanently dark. Annual running costs are expected to be about $\$ 10$ million. Competition for the management contract has been fierce after bidding was officially

opened by NASA at the beginning of last year. There seems, however, to have been little of the political squabbling that has surrounded decisions about major scientific facilities in the past, in particular the controversies over the siting of new particle accelerators.

AURA has made much of the local facilities offered by Baltimore, which has recently been going through something of an urban renaissance. It also stressed the proximity of the city to the Goddard Space Flight Center, from which the manoeuvring of the telescope will be controlled and at which a small team from the institute will be based.

In the end, however, location is thought to have played a relatively minor part in the decision. Princeton is not much further from Goddard, and both cities have access to major international airports - one of the preconditions stipulated by NASA.

More important seems to have been a quantitative assessment made by the evaluation team of the facilities and management support being offered in each case. Johns Hopkins was not able to match the strong astronomy department offered by Princeton. Several of its physicists, however, including some members of the Applied Physics Laboratory (APL), have been closely involved in the design of the space telescope and its instrumentation.

Following NASA's decision, AURA announced that the acting director of the institute will be Professor Arthur Code, at present professor of astronomy at the University of Wisconsin in Madison. The acting deputy director will be Dr Robert Rich of APL. Dr Arthur Davidson,

\section{Dutch partners for La Palma observatory}

The British Science Research Council may have found another collaborator for its optical astronomy observatory at La Palma in the Canary Islands. The Netherlands will probably join Spain, Sweden and Denmark in the collaboration to build and run the site. Last week, the council of the Netherlands Organization for the Advancement of Pure Research (ZWO) approved the deal "subject to contract", as the lawyers say. Professor Graham Smith, director of the Royal Greenwich Observatory which is coordinating the project, welcomes Dutch accession and thinks that the Netherlands may help especially with the supply of skilled manpower for management of the project.

The La Palma observatory, originally called the Northern Hemisphere Observatory, will eventually include our major British telescopes - a 1-m diameter Schmidt telescope, the 2.5-m Isaac Newton telescope (which is being transferred from Britain), a new 4.2-m telescope and a new $15-\mathrm{m}$ radio telescope. Four smaller professor of physics at Johns Hopkins, will be acting chief of the research support branch, and Dr William Fastie will be responsible for scientific instruments.

One factor which had concerned the AURA team while the proposals were being evaluated was the threat of federal action against Computer Sciences Corporation (CSC). The consortium had chosen the company to provide computer services, but CSC is under indictment for overcharging the federal government on time-sharing facilities.

Shortly before the management contract was awarded, however, NASA - having checked with the General Services Agency, on whose behalf the indictment has been filed - announced that although CSC has been suspended from bidding for future time-sharing contracts, it was still free to bid for technical support contracts, since these services were provided by another part of the company.

Johns Hopkins officials have welcomed the news about the institute. University president Steven Muller suggested that, given the dominant role that the space telescope is likely to play in optical observation until the end of the century, "there is true excitement at the prospect that Baltimore will now become the world capital of astronomy',

At Princeton, there was comparable disappointment. "To have hosted the institute would have been the next important step for the Princeton scientific community", one faculty member said last week. "Now we must go back and do some reassessing.",

David Dickson

instruments are being provided by Sweden and Denmark. Preparations for the observatory started in earnest eighteen months ago, after the protracted negotiations with Spain had been completed. Construction is well ahead, according to Professor Smith. The 1-m and the Isaac Newton telescopes are almost ready for removal to the Canary Islands and the observatory is on the verge of placing a contract for the mirrors for the 4.2-m telescope. A call has gone out to astronomers in several countries for the design of ancillary instruments for the 4.2-m telescope.

Successful bidders will be rewarded in part with observing time. The remaining contracts for the 4.2-m telescope are likely to be placed later this year, and the telescope could be working by the spring of 1985 , but that date could slip by a year if the cash flow of the Science Research Council does not improve.

Much of the negotiation between the Netherlands and Britain has already been completed. In return for 20 per cent of the 